University of Nebraska - Lincoln

DigitalCommons@University of Nebraska - Lincoln

USDA National Wildlife Research Center - Staff Publications
U.S. Department of Agriculture: Animal and Plant Health Inspection Service

2018

\title{
Objectives and integrated approaches for the control of brown tree snakes: An updated overview
}

Richard M. Engeman

USDA National Wildlife Research Center, s_r100@yahoo.com

Aaron B. Shiels

USDA National Wildlife Research Center

Craig S. Clark

USDA APHIS

Follow this and additional works at: https://digitalcommons.unl.edu/icwdm_usdanwrc

Part of the Life Sciences Commons

Engeman, Richard M.; Shiels, Aaron B.; and Clark, Craig S., "Objectives and integrated approaches for the control of brown tree snakes: An updated overview" (2018). USDA National Wildlife Research Center Staff Publications. 2130.

https://digitalcommons.unl.edu/icwdm_usdanwrc/2130

This Article is brought to you for free and open access by the U.S. Department of Agriculture: Animal and Plant Health Inspection Service at DigitalCommons@University of Nebraska - Lincoln. It has been accepted for inclusion in USDA National Wildlife Research Center - Staff Publications by an authorized administrator of DigitalCommons@University of Nebraska - Lincoln. 
Review

\title{
Objectives and integrated approaches for the control of brown tree snakes: An updated overview
}

\author{
Richard M. Engeman ${ }^{a,}{ }^{*}$, Aaron B. Shiels ${ }^{a}$, Craig S. Clark ${ }^{b}$ \\ a USDA/National Wildlife Research Center, 4101 LaPorte Ave., Fort Collins, CO 80521, USA \\ ${ }^{\mathrm{b}}$ USDA/APHIS/WS, 3375 Koapaka Street, Suite H-420, Honolulu, HI 96819, USA
}

\section{A R T I C L E I N F O}

\section{Article history:}

Received 19 December 2017

Received in revised form

20 April 2018

Accepted 22 April 2018

Available online 5 May 2018

\section{Keywords:}

Boiga irregularis

Detector-dogs

Endangered species

Invasive species

Integrated pest management

Transportation

\begin{abstract}
A B S T R A C T
After its inadvertent introduction to Guam, the brown tree snake (Boiga irregularis, BTS) extirpated most of the island's native terrestrial vertebrates, presented a health hazard to small children, and had considerable economic ramifications. Management of BTS is aimed at a number of objectives, the foremost of which has been to deter its dispersal from Guam to other locations. Further objectives include reclaiming areas on Guam as snake-free for reintroduction of native wildlife, to protect small sensitive sites on Guam from BTS intrusion (e.g, power stations, bird nesting sites), to contain and capture stowaway BTS incoming to vulnerable destinations, and to control incipient populations in other areas beyond their native range. A number of control tools have been developed, and the efficacy of each control method depends on the situation to which it is applied. Integration of control methods provides the most efficacious results for all objectives. Here, we outline the different objectives for managing BTS, and the tools and methods available for BTS management. We complete the picture by describing which tools and methods are best suited to accomplish each management objective.
\end{abstract}

Published by Elsevier Ltd.

\section{Contents}

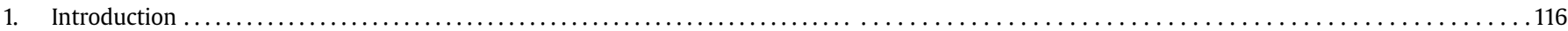

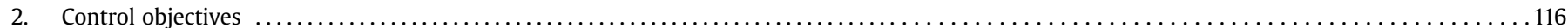

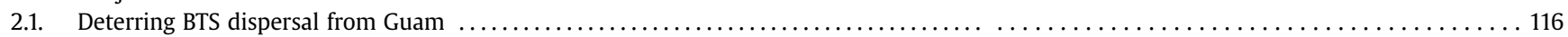

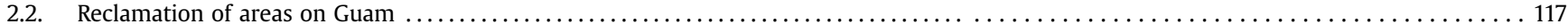



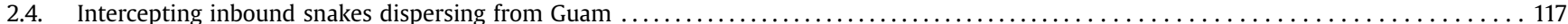

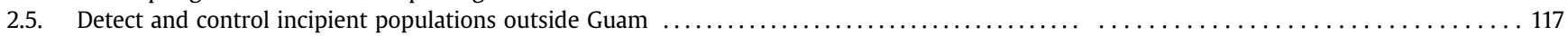

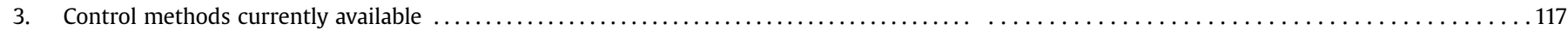

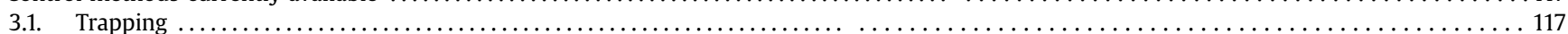

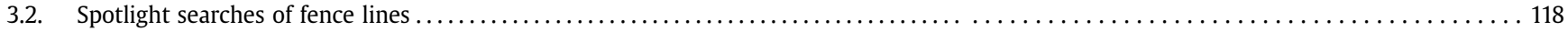



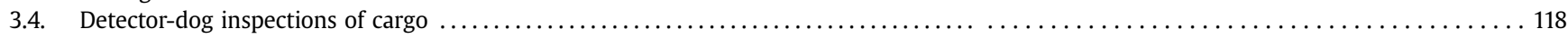

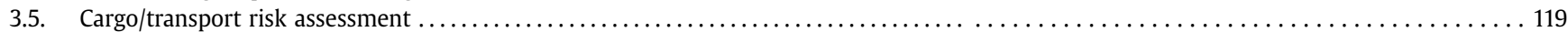

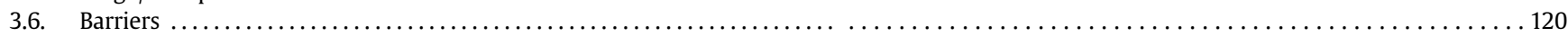

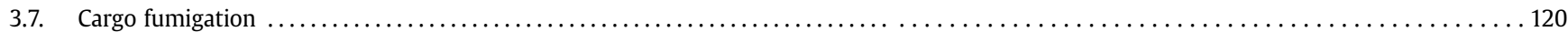

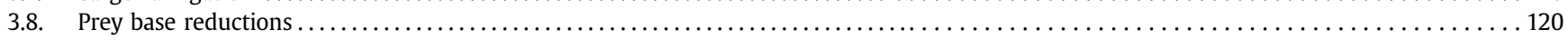

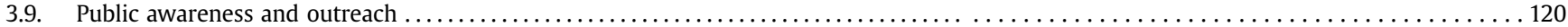

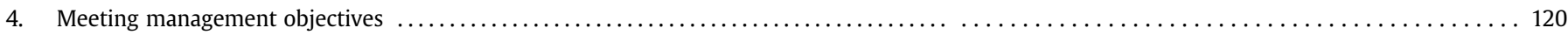

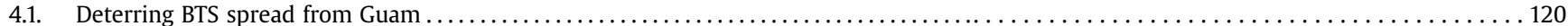

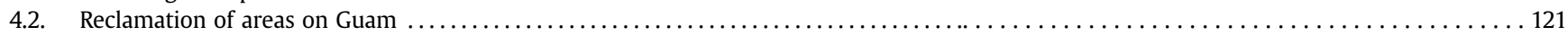

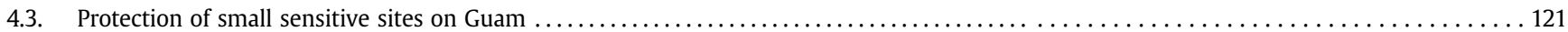

\footnotetext{
* Corresponding author.

E-mail address: richard.m.engeman@aphis.usda.gov (R.M. Engeman).
} 


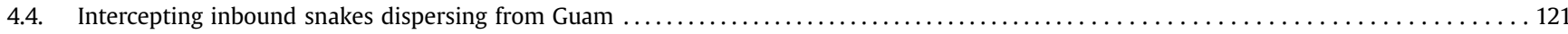

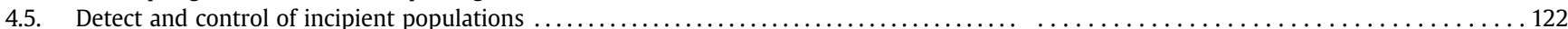

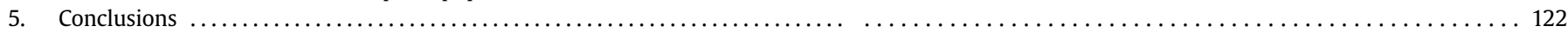

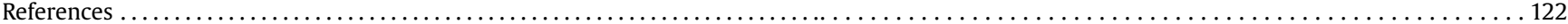

\section{Introduction}

The brown tree snake (Boiga irregularis, BTS) on Guam has produced a severe example of negative impacts to insular native fauna from an introduced predator. This snake was likely brought to Guam accidentally through post World War II shipments from New Guinea (Richmond et al., 2015). BTS are opportunistic feeders with a highly varied diet (e.g., Rodda et al., 1999; Savidge, 1988; Shivik and Clark, 1999). By the 1970's, native bird populations were absent from all but northern Guam (Grue, 1985; Savidge, 1987; Savidge et al., 1992), with the cause ultimately identified as predation by the BTS (Savidge, 1987). Guam's wildlife had already evolved resilience to dramatic habitat changes regularly inflicted by typhoons (Engbring and Pratt, 1985), but native birds and other species on Guam had not evolved in the presence of arboreal and nocturnal predators. In this environment, BTS populations achieved extraordinary densities and decimated native vertebrate species.

Of Guam's 12 native forest bird species, only Mariana grey swiftlets (Aerodramus vanikorensis bartschi) and Micronesian starlings (Aplonis opaca) presently survive in the wild. Guam rails (Gallirallus owstoni) and Micronesian kingfishers (Halcyon cinnamomina cinnamomina) were taken into captive breeding programs, and Mariana crows (Corvus kubaryi) are endangered and still survive on Rota, Commonwealth of Northern Mariana Islands (CNMI).

Guam's bat populations declined along with the bird populations. Guam's population of Mariana fruit bats (Pteropus mariannus), already impacted by hunting, were further decimated by BTS predation (Wiles, 1987a, 1987b; Wiles et al., 1995). Several indigenous or endemic lizard species became extinct or endangered due to BTS predation (Rodda and Fritts, 1992a).

Besides their ecological impacts, BTS are agricultural pests through depredations on poultry and other small domestic animals (Fritts, 2002; Fritts and McCoid, 1991). BTS cause frequent electrical power failures when they climb utility poles and wires and connect live and grounded wires. This causes significant economic losses from damaged electrical equipment, with associated repair costs and productivity losses (Fritts, 2002; Fritts et al., 1987). Furthermore, the BTS is mildly venomous, rear-fanged, and chews to envenomate its victims. It is primarily a health hazard to infants and small children, because they are less able to defend themselves when bitten, thereby allowing the snake to chew and envenomate. Life-threatening snakebite incidents with children have occurred on Guam (Fritts et al., 1990, 1994).

BTS are well-suited for transport to, and establishment at, other locations, thus threatening to impact those locations (e.g., Fritts et al., 1999). Its range on Guam encompasses the entire island, urban and rural areas alike. BTS are highly mobile, agile climbers that seek refuge during daylight. Cargo, shipping containers, and air and sea transport vessels potentially offer daytime refugia. Guam's position as a focal point for commercial and military shipments of cargo and passengers throughout the Pacific presents acute and chronic threats for further BTS dispersal (Vice et al., 2002), with sightings on other Pacific islands and elsewhere (Fritts et al., 1999).

The damage inflicted by BTS on Guam and the potential for its spread from Guam prompted management action against BTS. A variety of federal, state, and territorial agencies, as well as universities have conducted research to study the ecology of BTS and to develop tools and strategies for managing them. A wide variety of U.S. federal government entities, Guam Territorial, CNMI Commonwealth, and Hawai'i State governments, port and power authorities, and commercial enterprises have cooperated in BTS management. The vast majority of BTS management is carried out on Guam for these entities by cooperative agreements with the U.S. Department of Agriculture/Wildlife Services (WS), the Federal agency responsible for managing conflicts with wildlife (U.S. Department of Agriculture/Animal and Plant Health Inspection Service et al., 1997). Considering only the WS BTS operation on Guam, funding is provided by its cooperators, with funding ranging from $\$ 4.5$ million to $\$ 6.0$ million annually. The combination of management approaches to be applied depends on the circumstance and the management objective being addressed. In this review, we outline the different objectives for managing BTS, and the tools and methods available for BTS management. We complete the picture by describing which tools and methods are best suited to accomplish each management objective. This review serves to not only update the management objectives and approaches first presented by Engeman and Vice (2001b), but also presents considerable new information from the nearly two decades since that publication.

\section{Control objectives}

Here, we categorize and describe the different objectives for BTS management. In Section 3 (Control methods currently available) we describe the approaches available to achieve those management objectives. Concerted research to develop control tools and experience from a federal program implemented in 1993 to control BTS on Guam have furthered development, definition, and refinement of control procedures. Many control tools are applicable to multiple objectives and optimal integration of control methods varies according to objective (Table 1 ).

\subsection{Deterring BTS dispersal from Guam}

This management objective has received the most effort and attention. Its primary focus is protecting the Hawaiian Islands from invasion. Economic analyses indicated BTS establishment in Hawai'i could result in annual economic costs between \$593 million and $\$ 2.14$ billion (Shwiff et al., 2010). Federal control efforts were implemented on Guam in 1993 to address this objective (Hall, 1996; Ohashi and Oldenburg, 1992). The primary areas on Guam targeted for snake control included commercial and naval wharves, commercial and military airfield cargo facilities, warehouses and cargo staging sites, military storage, military housing (military base turnover presents large amounts of household move cargo) and areas where military exercises occur. The areas subjected to control have evolved with monitoring and an improved understanding of cargo traffic flows within and from Guam (Vice, 2011; Vice et al., 2002). 
Table 1

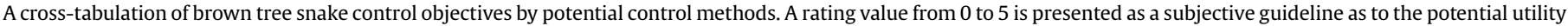
of individual control methods to each of the control objectives, where 0 indicates no or extremely low applicability and 5 represents highest applicability.

\begin{tabular}{|c|c|c|c|c|c|}
\hline \multirow[t]{2}{*}{ Methods } & \multicolumn{5}{|l|}{ Objectives } \\
\hline & Deter spread from Guam & Reclamation on Guam & Protect small sensitive sites & Contain inbound snakes elsewhere & Incipient population \\
\hline Trapping & 5 & 5 & 5 & 5 & 5 \\
\hline Oral toxicants (bait station) & 5 & 5 & 5 & $5^{a}$ & $5^{\mathrm{a}}$ \\
\hline Oral toxicants (aerial) & 2 & 5 & 0 & 0 & $1^{\mathrm{a}}$ \\
\hline Spotlight searches & 5 & 4 & 5 & 5 & 5 \\
\hline Detector dogs & 5 & 0 & 2 & 5 & 1 \\
\hline Cargo risk assessment & 5 & 0 & 0 & 5 & 0 \\
\hline Barriers & 4 & 4 & 5 & 5 & 3 \\
\hline Prey base reductions & 4 & 4 & 4 & 2 & 2 \\
\hline Public awareness & 5 & 3 & 4 & 5 & 5 \\
\hline Cargo fumigation & 1 & 0 & 0 & 0 & 0 \\
\hline
\end{tabular}

${ }^{a}$ Assumes necessary environmental regulations have been met.

\subsection{Reclamation of areas on Guam}

This objective returns areas on Guam to pre-BTS condition by removing BTS and maintaining such population reductions. This benefits existing native wildlife and provides more secure habitat where captive-bred species might be reintroduced. A 24 ha site on Andersen Air Force Base (AFB) was the first reclamation, and other areas received severe snake reductions (Anderson et al., 1998; Beauprez and Brock, 1999; Lynch et al., 2001; USDoD, 2008; Vice et al., 2001).

\subsection{Protection of small sensitive sites on Guam}

Similar but on a smaller scale is the removal and exclusion of BTS from small but especially sensitive sites on Guam. Primary examples include preventing BTS intrusion into power stations, or nesting trees and caves used by endangered birds (Aguon et al., 1998, 1999; Clark and Vice, 2001; Vice et al., 2001). Not only is the geographic scale for this objective less than for the previous objective, but for some situations the protection can be temporary, although recurring. For example, nesting trees and caves only need protection while nesting activities are ongoing. Outside of then, there is no overriding need to protect those sites until the next nesting season.

\subsection{Intercepting inbound snakes dispersing from Guam}

BTS have occasionally arrived alive from Guam at various places elsewhere in the world (McCoid et al., 1994). Preventing new arrivals from escaping beyond port areas is crucial, considering DNA evidence suggests the Guam population may have resulted from very few introduced individuals (Rawlings et al., 1998; Richmond et al., 2015). Moreover, costs for containment of new arrivals would be far less than to later control an incipient population, especially since control methods reliant on food-related baits or attractants may not attract BTS in such locations beyond Guam with prey-rich environments.

\subsection{Detect and control incipient populations outside Guam}

Detection and control of incipient populations outside Guam before they grow into a greater problem is essential. This cryptic species' nocturnal habits and secretive behavior during the day makes detecting an incipient population difficult. Incipient population densities would be infinitesimally small compared to Guam, with detection probabilities correspondingly small. Intense application of multiple methods would be required to overcome small contact probabilities. Here too, control methods reliant on food- related baits or attractants may not appeal as much to BTS in new locations beyond Guam with prey-rich environments.

\section{Control methods currently available}

A variety of control methods have been developed and implemented for BTS. Operational efficacies of some methods are welldocumented. However, considerable research has been directed towards improving efficiencies of existing methods, as well as developing new methods. Control methods complement each other, and when used in varying combinations provide optimal outcomes for each objective.

\subsection{Trapping}

Trapping has long been central to control activities on Guam (e.g., Engeman et al., 1998a). Funnel trap designs, first applied to protect waterfowl nests from bullsnakes (Pituophis melanoleucas) (Imler, 1945), and similar to commercial minnow or crayfish traps, were developed for BTS capture by installing one-way door flaps at entrances on both ends (Linnell et al., 1998). A live mouse, fully protected in an interior cage, served as the lure. The trap design has evolved considerably to improve efficacy while reducing costs and labor. Modified two-piece, crayfish traps were replaced by onepiece, custom-designed traps where the mouse cage is integrated into the trap wall. The per-trap cost for the initial installation of a single trap was estimated in 2002 to cost US\$65, with trap fabrication and shipping accounting for approximately US\$55 of those costs (Vice and Pitzler, 2002). Mouse care takes place without opening the trap body, reducing maintenance times (Fig. 1; Vice et al., 2005). Procedures and conditions are excellent for mouse survival, with life expectancies similar to other captivity settings (Vice et al., 2005). Multiple large snakes readily enter traps; one trap simultaneously captured snakes 1.5, 2.1, and $2.2 \mathrm{~m}$ long (Engeman and Vice, 2001b).

Trap placement can affect control efficacy. Perimeter trapping around forested plots results in much higher capture rates than traps placed within the plots, conceivably because snakes in fragmented forested plots frequently encounter forest edges and remain along the forest perimeter (Engeman and Linnell, 1998). Perimeter trapping does not require cutting trails in the forest and permits vehicle access for trap maintenance, making trapping less labor-intensive and thereby allowing more traps to be placed and a greater geographical area to be addressed. Perimeter trapping also has minimal impact on native vegetation. After snake population reduction, maintaining strategically placed traps around plots deters population recovery (Engeman and Linnell, 1998).

Optimal trap spacing is not well understood. Perimeter trapping 


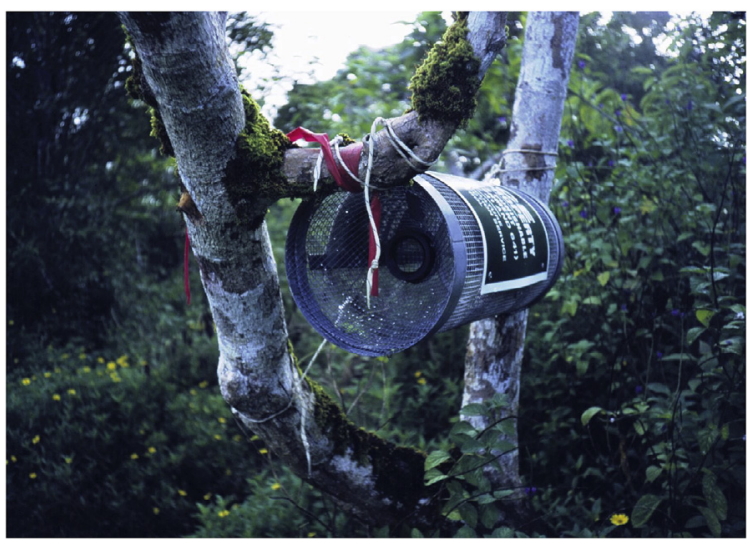

Fig. 1. Brown tree snake trap installed on forest perimeter in Guam. (Photo by R. Engeman).

capture rates did not differ among inter-trap spacings of 20, 30 and $40 \mathrm{~m}$ (Engeman and Linnell, 2004). However, study plots were narrow with high perimeter to area ratio, increasing the likelihood snakes would be on forest perimeters where traps were placed.

As plot dimensions increase, the likelihood diminishes for perimeter trapping to effectively capture snakes in the plot center. The maximal plot size for which perimeter trapping is effective is unknown, although perimeter trapping effectively removed the snakes from a 17.8 ha trapezoidal-shaped plot in 7.5 mo (Engeman et al., 2000). As the perimeter to area ratio for a plot increases, so does perimeter trapping efficacy.

\subsection{Spotlight searches of fence lines}

Spotlight searches for capturing BTS from fence lines efficiently removes large numbers of snakes, accounting for up to 25\% of BTS taken by WS control staff annually across Guam (Vice, 2011). Most port areas, other cargo staging locations, and restricted areas are surrounded by extensive fence lines. BTS are arboreal and readily ascend fences, making them easily detected in spotlight beams (Fig. 2). Rodda (1991) found snakes released near a fence with low vegetation on both sides were highly likely to climb the fence (77\%). In contrast, detecting and capturing the cryptically colored BTS was found to be very difficult and impractical for routine control when spotlighting the usually dense vegetation on forest edges (Rodda and Fritts, 1992b). Typically, fences searched along most

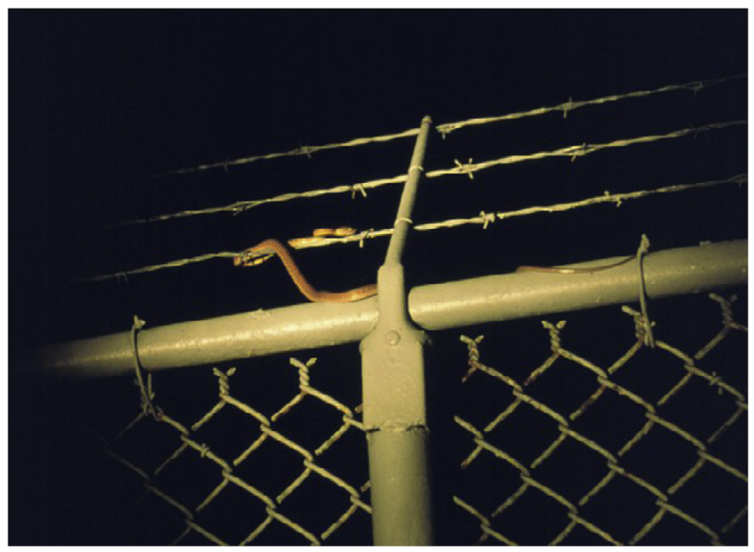

Fig. 2. Brown tree snake caught in a spotlight beam on a fence on Guam. (Photo by R. Engeman). properties on Guam regardless of administrative authority are chain-link fences with 3 parallel strands of barbed wire on outriggers above the chain link. A horizontal bar or cable usually supports the top of the chain link. Fences usually have suitable topography with cleared vegetation to permit vehicle access.

In a study that examined the positioning of over 600 BTS captured from fences across Guam by WS, snakes were most often horizontal (resting or traveling), suggesting BTS use fences as travel pathways (Engeman et al., 1999). Prior to this research, Rodda (1991) speculated that BTS used fences to forage for geckos. The use of fences as travel pathways makes spotlight searches all the more valuable for detecting and controlling incipient BTS populations (Engeman et al., 1999). Snakes found after arriving in locations beyond Guam were often associated with cargo facilities, where vegetation is sparse and fences are invariably present. Fences may be the first structures snakes could climb, making them critical to search following a snake report.

Spotlight searches also complement trapping for removing snakes. Captures by trapping decrease exponentially over time, but captures by spotlighting fences tend to consistently produce captures at low levels (Engeman and Vice, 2001a). Spotlight searches in areas with extensive fence lines have been a valuable means to remove substantial numbers of BTS ( 1200 per year) (Engeman et al., 1999; Vice, 2011).

\subsection{Baiting with oral toxicants}

Many commercially available products have been tested for oral toxicity to BTS (Brooks et al., 1998a, 1998b). Rotenone, propoxur, natural pyrethrins, allethrin, resmethrin, diphacinone, warfarin and aspirin were found to be orally toxic to BTS (Brooks et al., 1998b). Of three subsequently tested non-narcotic analgesic drugs delivered in dead neonate mice (DNM) as a matrix (Savarie et al., 2000, 2001c), only acetaminophen was highly effective (aspirin was moderately effective, and ibuprofen was ineffective). Snakes ingesting an $80 \mathrm{mg}$ dose died in less than $48 \mathrm{~h}$ (Savarie et al., 2001c).

Commercially available DNM are very effective for delivering acetaminophen to BTS in the field (Savarie et al., 2001c). DNM baits are so well accepted by BTS that bait take is a reliable method for monitoring BTS abundance (Clark et al., 2012). No evidence of primary or secondary hazards to non-target native species have been found (Avery et al., 2004; Savarie et al., 2000, 2001a, 2001b). Moreover, baits deteriorate in 2-3 days in Guam's climate. Due to its efficacy and safety, acetaminophen was registered with the U.S. Environmental Protection Agency (EPA) for use in a DNM matrix (Fagerstone and Eisemann, 2001). Two bait delivery methods have been developed. One uses bait stations highly selective for entrance by BTS (Fig. 3). The other is aerial bait distribution using biodegradable devices to hang baits in canopy vegetation where they would most likely be encountered by BTS. Similar to trapping, bait stations on plot perimeters with similar spacing as traps have been found to be an efficient and effective strategy for suppressing the snake population inside the plots (Savarie et al., 2001c; Clark et al., 2012). Aerial baiting holds promise as an economical and selective method for reducing BTS populations over large landscapes with little non-target risk (Clark and Savarie, 2012). A recent 16-month assessment of aerial acetaminophen toxicant delivery using 55 ha forested plots demonstrated aerial application of acetaminophen treated baits can reduce BTS numbers even over large or inaccessible areas (Dorr et al., 2014, 2015).

\subsection{Detector-dog inspections of cargo}

While trapping, toxic baits, and spotlight searches are effective 


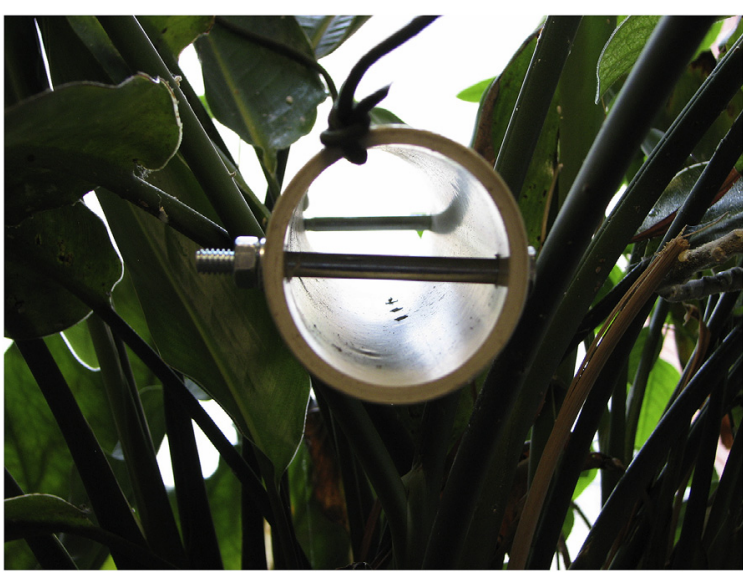

Fig. 3. Bait station (unbaited) to selectively deliver highly effective acetaminophen in a dead neonate mouse to brown tree snakes (Photo by P. Savarie).

against snakes in urban or forested areas, they do little to affect snakes stowed-away in outbound cargo. In these situations, trained dogs are used to locate and remove BTS from outbound cargo (Fig. 4). Each detector-dog team is comprised of a handler and a dog assigned to that handler. A variety of commercial and military locations are inspected. Household commodities waiting to be containerized for household moves via surface transport (i.e., household goods, vehicles) are inspected at least once during daylight hours on the day scheduled for containerization. Aircraft are typically inspected within three hours of scheduled departure. General freight is inspected daily, regardless of the scheduled departure date. Commercial cargo to be containerized is inspected immediately prior to containerization (Vice, 2011). Around 99\% of Guam's outbound cargo is inspected by WS detector dog teams. Also, at some locations, like the CNMI and Hawai'i, which are at high risk for accidental importation of BTS from Guam, detector dog teams inspect inbound cargo (e.g., Saipan Tribune Press Release, 2017; Office of Insular Affairs/U.S. Department of Interior, 2015; Vice et al., 2009).

Records of BTS detected during dog inspections revealed that, based on proximity to outbound cargo or transport vessels, $80 \%$ were at high risk for export, with Hawai'i and Micronesian islands most frequently identified as potential destinations (Engeman et al., 1998b; Vice and Engeman, 2000). The efficacy of dog teams for locating stowed BTS was investigated by planting live BTS (in escape-proof containers) in cargo without the knowledge of

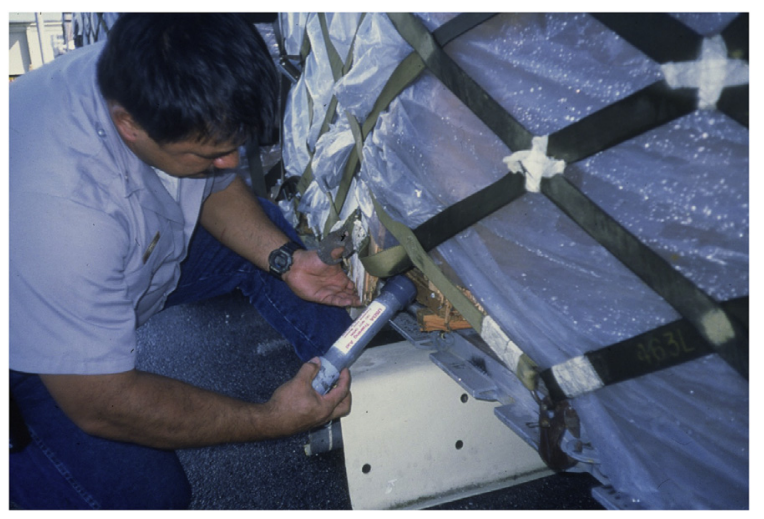

Fig. 4. Planting a brown tree snake in an escape-proof container in cargo to test detector dogs and their handlers for locating stowed snakes before they could depart Guam. (Photo by R. Engeman). handlers responsible for inspecting the cargo (Engeman et al., 1998d, 2002). This percentage was likely a conservative estimate for detection of BTS naturally entering cargo for a couple reasons. First, planted BTS are in escape-proof containers that restrict air currents that might carry their scent to the dogs. Second, the snakes are placed into position manually, which means they leave no scent trails for the dogs to pick up or follow. After such plantings became routine, $70 \%$ of the planted snakes were discovered at that time. Reasons dog teams missed planted snakes were split between insufficient search patterns by handlers (i.e., incomplete or too fast searches, where the handler did not thoroughly direct the dog through the search) or the handler not detecting an indication from the dog. The interaction between dog and handler is complex making it impossible to precisely determine in the latter case whether: 1) the snake wasn't detected by the dog, 2) the dog detected the snake but did not respond, or 3 ) the handler did not recognize the dog's response. Continued testing found fewer missed snakes were due to insufficient search patterns (Engeman et al., 2002). As training has progressed over the intervening years, training tests with planted BTS have seen steady improvements in detection rates to $81 \%-93 \%$.

Finding planted snakes instills confidence in dogs from their handlers. Similarly, facility workers and managers have expressed increased confidence and interest in the abilities of handlers and dogs, leading to proactive snake control efforts by employees at inspected facilities (Engeman et al., 1998d). Consistent, relevant training is crucial, and all handling teams on Guam undergo periodic proficiency training and are tested annually. This has resulted in increased snake detection rates in the quality assurance program (Vice et al., 2009). While a small amount of outgoing cargo is not inspected by detector-dog teams and it also is impossible to know if a snake went undetected in cargo during an inspection, the efficacy of the Guam program is indicated by detector-dog inspections of cargo inbound from Guam not having detected live BTS in either Hawai'i or the CNMI, nor have live BTS been confirmed in Hawai'i by any means since 1994 .

Challenges facing detector-dog inspections include task monotony and maintenance of vigilance, the economics of vessel delays due to inspection times or search times following a positive dog response, and protocol for handling cargo where no snake was found after a positive response. These issues are more acute at recipient locations where the probability of locating a snake appears extremely low, but the cost of BTS establishment is very high (Vice et al., 2009).

\subsection{Cargo/transport risk assessment}

Means by which snakes could be transported off Guam to vulnerable locations are identified to further define the threat of BTS dispersal from Guam. The type, amount, frequency, and primary destinations of cargo leaving Guam are continually monitored to identify changes in handling processes and procedures. Other factors for prioritizing risk include type of packing, storage (cross contamination potential), location and environment of storage facilities, transportation method, origination points and transit time (Vice et al., 2002). Data on environmental conditions in airplane wheel wells, transport vessels, and cargo containers over various trip lengths by various transport modes have helped further assess the risk that BTS could arrive alive at vulnerable destinations (Perry and Vice, 1998; Perry et al., 2001). This information allows management resources to be optimally directed to have greatest efficacy. 


\subsection{Barriers}

BTS are remarkable climbers. Nevertheless, suitably effective barriers could prevent intrusion by BTS to contained resources (exclusionary barrier) or keep snakes confined within a defined area (containment barrier) (Vice, 2011). Barrier applications include protecting port and cargo staging areas for outbound cargo on Guam from snake entry, containing snakes arriving from Guam at ports of entry, and protecting sites such as endangered species habitats, power stations, and poultry production areas. Lastly, barriers could help direct snakes to traps or toxicant delivery devices (Engeman and Vice, 2001b).

Due to the variety of barrier applications, there are a variety of barrier materials and designs. Three characteristics useful in effective barrier design are smooth materials, height, and overhang (Perry et al., 1998). Should a BTS breach a barrier, its design should allow the snake to return without difficulty (Perry et al., 1998). The ability of barriers to resist or deflect damaging winds, particularly in these tropical environments, is also highly desirable.

The duration of time a barrier will be required is the foremost determinant for barrier materials and design. Barriers are considered either permanent or temporary (Vice, 2011). Short-term needs such as one-time military exercises or some construction sites may require only temporary barriers that are easily transportable, quickly assembled, and relatively inexpensive. These tend to be less effective and less durable than permanently installed barriers (Perry et al., 1998). The question of duration also affects the construction design for permanent barriers, as areas such as ports or military bases may be redesigned frequently, requiring "permanent" barriers to be repeatedly reconstructed. Other important criteria for selecting construction design for permanent barriers include whether structures such as fences exist for barrier attachment, difficulty of terrain, need for visibility through a barrier (i.e., security), and cost.

Barrier use is challenged by both BTS climbing abilities and maintenance in the field. Damage by typhoons and animals also must be considered. Overgrowth of tropical vegetation provides points for easy BTS breaches. Therefore, barriers require accompanying inspection and maintenance.

Temporary barriers have been most commonly used with U.S. military exercises on Guam (Perry et al., 1998; Vice, 2011). Permanent barriers have been thoroughly tested, but implementation on Guam has been constrained by lack of resources and willingness by property managers to construct them (Vice, 2011). For large areas, barriers highly resistant to breaches might be cost-prohibitive. Less efficacious barriers integrated with other control methods might be cost-effective, while providing necessary protection (Engeman and Vice, 2001b).

\subsection{Cargo fumigation}

Another potential means for deterring BTS dispersal from Guam is to apply a toxic fumigant to outbound cargo that is effective against BTS, especially products already registered with EPA for cargo fumigation against other pests that demonstrate high efficacy against BTS (Engeman and Vice, 2001b).

Methyl bromide, sulfuryl fluoride and phosphine fumigants used for pests world-wide, were found effective against BTS in cargo containers (Brooks et al., 1998c; Savarie et al., 2005). BTS were added to the product label registered with EPA for methyl bromide (Brooks et al., 1998c). Several pyrethrin/pyrethroid insecticide foggers were not effective at killing BTS in cargo containers, although snakes directly exposed to pyrethrin fog droplets were killed (Brooks et al., 1998c).

However, because fumigants for cargo containers are highly toxic, expensive, and time consuming to apply, there is little current demand for their use. Until an inexpensive, easy-to-apply fumigant/fogger that is highly effective for BTS in packed cargo containers is developed, or fumigation legally mandated, cargo fumigants will have limited potential for application.

Thermal fumigation, however, has potential as a cargo treatment to eliminate BTS. Kraus et al. (2015) found BTS left refugia when streams of heated air were applied. Temperatures $48-52{ }^{\circ} \mathrm{C}$ at $3.4 \mathrm{~m}^{3} / \mathrm{min}$ caused snakes to exit within $5 \mathrm{~min}$. Development of a portable heat-delivery system that is logistically and economically practical would help further deter snakes from stowing in cargo. Applications could take place on Guam and recipient locations (Kraus et al., 2015). Applications on Guam would have maximal utility for preventing BTS reentry after treatment if physical barriers were in place and/or the time lag until shipment was minimized.

\subsection{Prey base reductions}

Introduced birds and rodent species are removed from civilian and military ports on Guam to decrease attraction to BTS (Vice, 2011). Cage traps and air rifles are used to reduce numbers of Eurasian tree sparrows (Passer montanus), black drongos (Dicrurus macrocerus), and feral pigeons (Columba livia) (Engeman and Vice, 2001b; Vice, 2011). EPA-registered toxic baits in tamper-proof containers are also used against rodents (Vice, 2011).

BTS removal from an area can be followed by an increase in rodent populations (Engeman et al., 2000). Increased rodent populations increase BTS food resources and could attract snakes back into the area. Thus, nonnative prey base reductions can augment BTS removal longevity and efficacy where feasible. Moreover, rats can pose substantial hazards to endangered birds (e.g., Buckle and Fenn, 1992), and reducing their populations would also be important for reclaiming land for endangered species reintroductions (Engeman et al., 2018). Reducing nonnative prey where feasible in potential recipient locations for BTS could also enhance attractiveness of mice in traps or DNM in bait stations.

\subsection{Public awareness and outreach}

Education and enlistment of the public and military on Guam, and at transport destinations from Guam, provide vital support for meeting BTS management objectives (Engeman and Vice, 2001b). The effects of BTS have been published through popular media, and these generate public awareness and support for BTS control efforts, as well as facilitating control efforts through public detections of snakes, or directly controlling snakes. Flyers, brochures, videos, educational television commercials, workshops, seminars, and live detector-dog demonstrations are useful educational and outreach tools for promoting public involvement in BTS control. The military produced pocket brochures describing the responsibilities of personnel towards the environment, with an emphasis on preventing BTS spread. Moreover, the Government of Guam Department of Agriculture provided snake traps to the public at no cost. Nearly half of BTS discovered in cargo were found by persons not associated with Guam's BTS program, reinforcing the importance of outreach and awareness training of employees (Vice, 2011).

\section{Meeting management objectives}

\subsection{Deterring BTS spread from Guam}

Containment efforts are concentrated in cargo packing, handling, and staging "bottlenecks," where control activities offer maximum benefit (Vice, 2011). This approach offers the most 
efficient delivery of services and resources, without spreading them too sparsely. Aircraft, ocean-going vessels, and cargo and materials associated with air and surface transportation are subjected to varying levels of containment. Snake removal by trapping, toxic baits, spotlight searches, and detector-dog inspections are integrated to maximize efficiency and to minimize the scenarios where BTS could evade controls and depart Guam (Engeman and Vice, 2001b). Augmentation with passive deterrence measures, such as barriers, plus continued refinements and optimization of application strategies improves effectiveness. Understanding snake survivability in transit from Guam, in-depth knowledge of cargo flows from Guam, and a public awareness to cooperate with snake control efforts allow precise control strategies and efficient application of control methods. Implementation and continued improvements of control methods have greatly reduced BTS access and stowing in transportation from Guam to vulnerable destinations. Although effective, currently used methods can be labor intensive. Means to make existing methods more efficient and/or more effective would enhance control efforts. The attraction distance for traps is not clearly defined, but if greater than trap spacing, then increased distances between traps could extend applications or increase trapping efficiency. Acetaminophen aerially delivered in DNM appears poised to be added soon as a control tool. This toxicant delivery system offers wider-scale snake control on Guam. Additional practical methods that also complement existing tools in an integrated program could improve prevention of BTS dispersal from Guam. Artificial replacements for live mice in traps and DNM as a bait matrix could greatly reduce labor, allowing placement of many more traps and baits (Savarie, 2012; Savarie and Clark, 2006). Considerable testing of potential artificial substitutes for DNM baits has taken place with encouraging results using a processed meat bait treated with an artificial mouse fat mixture (Kimball et al., 2016; Savarie, 2012; Savarie and Clark, 2006). Repellents to deter entry into cargo and irritants (including thermal vectors) to drive snakes from cargo would be major assets to cargo inspections with dogs and would more convincingly assure cargo is snake-free (Clark and Shivik, 1998, 2002).

\subsection{Reclamation of areas on Guam}

BTS removal to reclaim areas on Guam has been limited. A 24 ha site on Andersen AFB was largely reclaimed through trapping and excluding re-invaders with a wire mesh barrier attached to a fence (Anderson et al., 1998, Fig. 5). Guam rails were reintroduced and reproduced (Vice et al., 2001), but feral cats (Felis catus) doomed the reintroduction (Beauprez and Brock, 1999; U.S. Fish and Wildlife

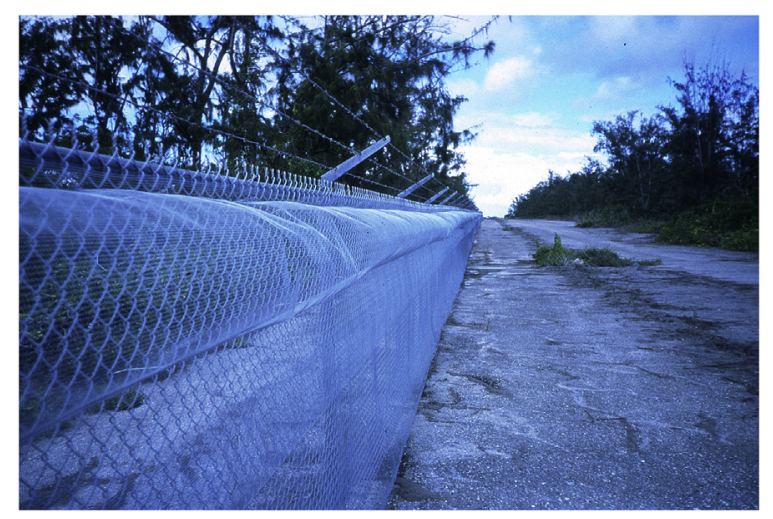

Fig. 5. Example of a permanent brown tree snake barrier attached to a chain link fence. Wire mesh prevents crossing through the fence and the wire mesh bulge creates an overhang the snakes cannot climb over. (Photo by R. Engeman).
Service, 2009). A similar result occurred when rails were reintroduced into another snake-reduced area on Andersen AFB (U.S. Fish and Wildlife Service, 2009). Continued improvements in BTS removal methods will allow more and larger areas for reclamation on Guam. Reclamation will rely heavily on trapping and toxic baits, although areas with fences allow snake removal to be augmented with spotlight searches. The use of detector dogs appears impractical for this objective, considering tests using a radio-transmitterattached BTS only had a 35\% canine detection rate in a $40 \times 40 \mathrm{~m}$ forested plot (Savidge et al., 2011). As larger areas are targeted, perimeter trapping and baiting would be applied around the exterior of the reclamation area. The use of trapping for large-scale BTS population reduction has met mixed reviews. Rodda et al. (1998) labeled trapping on a landscape scale as a "seductive loser," basing that opinion on economics of simultaneously trapping very large areas. However, the application of such a label is unfortunate as it did not consider trapping as practiced operationally as a component in an integrated control program that simultaneously applies multiple control methods, and it also did not consider trapping in a sequential, strategic approach that would be practical for snake removal over large areas. Aerially broadcasting baits offers much more cost-effective and less laborintensive snake removal from interiors of large plots (Clark et al., 2012; Dorr et al., 2014, 2015). The perimeter strategy for applying traps and bait stations has proven adequate for eliminating BTS from smaller plots (e.g., Engeman and Linnell, 1998). Where feasible, barriers could deter reoccupation by snakes, and some traps and bait stations should remain for the same purpose.

Rodent population reductions will be important because they often increase exponentially without controls, natural or otherwise. Large rodent populations would negatively impact endangered birds and attract BTS to re-invade. Thus, managers responsible for reclaiming land areas or protecting endangered species from BTS must consider the potential for rodent population management as BTS numbers are reduced.

\subsection{Protection of small sensitive sites on Guam}

It is essential that BTS do not intrude into many small sites on Guam, including many power stations and the few caves where endangered Mariana gray swiftlets nest. Barriers could be important for deterring entry into some sites. Reducing the numbers of snakes available to test barriers reduces the probability for breaches. Thus, BTS control by trapping and placing toxic baits nearby sensitive sites would complement barrier deployment. Power stations typically are enclosed by security fences, making spotlight searches complementary with other methods. Staff working to protect endangered species on Guam are acutely aware of BTS issues, but awareness programs for employees and occupants at other affected locations would enlist valuable help towards control efforts. Even if the public does not directly control BTS, their vigilance would be helpful in reducing vandalism of control materials.

\subsection{Intercepting inbound snakes dispersing from Guam}

Live BTS have previously been discovered in many vulnerable locations beyond Guam, usually in port areas. However, the control program has diminished the flow of snakes from Guam. For example, no live BTS have been discovered in Hawai'i since 1994, and no live BTS have been found in cargo there since implementation of Guam's detector dog program in 1993. Probabilistic reasoning suggests that the large volume of commercial and military cargo traffic through Guam could still occasionally result in snakes arriving alive at vulnerable destinations. Given this and the 
genetic implication that very few BTS can initiate a population (Rawlings et al., 1998; Richmond et al., 2015), it is vital to contain inbound snakes within these areas. Permanent containment barriers around air and sea port cargo and vessel handling areas could deter dispersal from these areas. Strategically applied detector-dog inspections of inbound cargo and vessels from Guam could also defend against snake dispersal from ports. Irritants, if fully developed, would be useful for insuring inbound cargo does not contain snakes. Public awareness, especially for port employees and other cargo handlers, would be essential for locating and controlling inbound snakes. Printed materials such as brochures and posters have been distributed in potential recipient locations like Hawai'i and the CNMI by various agencies and organizations. Many articles about BTS and their threats have appeared in potential recipient locations and many websites offer information about BTS. Public awareness of costs from BTS introduction (Shwiff et al., 2010) could help assuage local authorities that preventative measures are more cost-effective long-term than detecting and controlling a resultant incipient population.

\subsection{Detect and control of incipient populations}

Fortunately, there are no other known large invasive BTS populations outside Guam, however there is a concern that an incipient population exists on Saipan (Kraus, 2009; McCoid et al., 1994). Nevertheless, having to eventually respond to and remove a newly established breeding population is a realistic prospect. There are two goals for applying control tools to incipient populations. The first is to identify or confirm at the earliest possible stage that a BTS introduction has occurred, including the extent of their range (dispersal). The next step would be to isolate them, if possible, and remove them. Detection of initial BTS establishment will probably include snake sightings by the public. A campaign would be needed to alert the public that snakes should be killed or restrained, and authorities notified.

A multi-agency BTS Rapid Response Team that is based on Guam maintains a trained network of rapid responders to respond to potential sightings throughout the Pacific region. The team has over five dozen members situated around the Pacific region, conducts training both on and off Guam to respond to BTS sightings, and works with regional island groups to improve communication networks and raise public awareness (Stanford and Rodda, 2007). Spotlight searches, bait stations, and trapping would probably be the primary means to detect and control incipient populations. Detector-dogs might be applied if the geographic scale is practical for dog searches. A colonial population would have low density, making the probability of detecting and capturing a BTS correspondingly low for control methods such as traps, bait stations, or spotlight searches. If attraction to traps and bait stations is reduced in prey-rich environments, intensive spotlight searches of fences could be particularly valuable for detecting pioneering populations, defining their range, and removing them. Even though spotlight searches of forest edges have proven much more difficult and less efficacious than searches of fences on Guam, all feasible means must be applied to eliminate an incipient population. Fences can be designed and maintained to effectively assist BTS capture and control (Engeman et al., 1999; Hall, 1996; Rodda, 1991). Chain link fences constructed with a bar on top and parallel strands of wire above maximize spotlight search efficiency by concentrating snakes at fence tops. Fences should be maintained free of vegetation and have an adjacent buffer of mowed vegetation. Vegetation obscures observability of snakes, while mowed buffers facilitate searches from vehicles and promote fence climbing behavior. Even with diminished efficacy of traps and bait stations in new environments, intensive applications of both methods should take place in areas suspected of BTS colonization. Continued testing of pheromone attractants could yield a valuable tool for prey-rich circumstances (Mathies et al., 2013). If a discrete BTS site is small enough and environmental conditions allow, barriers could contain the population and control methods could be applied within.

\section{Conclusions}

Proper integration of available control tools (Table 1) has effectively deterred the spread of BTS from Guam. From 2007 to 2017 the specialists with WS removed 232,686 BTS from Guam with zero reported escaping off island (R. Gosnell, personal communication). Probably the most valuable measure of efficacy at deterring BTS spread from Guam has been that no live BTS have been discovered in Hawai'i since 1994, and that no live BTS have been found in cargo since implementation of Guam's detector dog program in 1993. BTS removal to reclaim areas on Guam has been shown feasible, although endangered species reintroduction into such areas would likely require control of additional invasive species such as feral cats and rats. Aerial distribution of acetaminophen baits will greatly increase the efficiency of such efforts, which can be labor and resource intensive. Similarly, small sensitive sites are able to be substantially protected. Protecting all such sites would require considerable resources. Thus, sites must be prioritized for receiving protection. New tools that reduce labor and expense potentially would allow the control program on Guam to be expanded or applied more intensively. At potential recipient locations, the objectives of intercepting BTS inbound from Guam or controlling incipient BTS populations can only be truly tested when a BTS is known to have arrived or an incipient population is known to exist. Nevertheless, it is the cadre of tools and methods already applied on Guam that would be available in such circumstances. Thus, the best options for addressing these objectives is to apply the appropriate control tools known to be effective on Guam. Here too, new methods to make control more efficient would permit more extensive and thorough application of control. There also are a variety of control tools that, if developed to be practical, would greatly aid all objectives. These include development of highly effective artificial baits and lures, pheromone attractants, BTS irritants, and BTS repellents.

Managing BTS to deter further range expansion from Guam and to protect and reclaim areas and resources on Guam is the world's first large-scale invasive snake management effort. As such, the methods and concepts for addressing BTS provide a foundation and model for developing invasive snake management efforts elsewhere, such as for the invasive Burmese pythons (Python bivittatus) in Florida (Engeman et al., 2011).

\section{References}

Aguon, C.E., Campbell III, E.W., Morton, J.M., 1998. Efficacy of electrical barriers to protect Mariana crow nests. In: Campbell III, E.W., Rodda, G.H. (Eds.), Brown Treesnake Research Symposium. 27-29 July, Honolulu, p. 10.

Aguon, C.E., Beck, R.E., Ritter, M.W., 1999. A method for protecting nests of the Mariana crow from brown treesnake predation. In: Rodda, G., Sawai, Y Chiszar, D., Tanaka, H. (Eds.), Problem Snake Management: Habu and Brown Treesnake. Cornell Univ. Press, Ithaca, NY, pp. 460-467.

Anderson, R.D., Beauprez, G.M., Searle, A.D., 1998. Creation of a snake-free area on Guam using trapping and barrier technology. In: Campbell III, E.W., Rodda, G.H. (Eds.), Brown Treesnake Research Symposium. 27-29 July, Honolulu, p. 10.

Avery, M.L., Tillman, E.A., Savarie, P.J., 2004. Responses of captive fish crows (Corvus ossifragus) to acetaminophen baits and bait stations for brown tree snake (Boiga irregularis) control on Guam. Bird. Behav. 16, 1-6.

Beauprez, G.M., Brock, M.K., 1999. Establishment of populations of endangered species in snake-free areas. In: Davis, G.W., Pitlik, T.J., Wiles, G.J. (Eds.), Annual Report Fiscal Year 1999, Division of Aquatic and Wildlife Resources. Guam Department of Agriculture, Mangilao, Guam, pp. 164-169.

Brooks, J.E., Savarie, P.J., Bruggers, R.L., 1998a. The toxicity of commercial insecticide aerosol formulations to brown tree snakes. Snake 28, 23-27. 
Brooks, J.E., Savarie, P.J., Johnston, J.J., 1998b. The oral and dermal toxicity of selected chemicals to brown tree snakes. Wildl. Res. 25, 427-435.

Brooks, J.E., Savarie, P.J., Johnston, J.J., Bruggers, R.L., 1998c. Toxicity of pyrethrin pyrethroid fogger products to brown tree snakes (Boiga irregularis) in cargo containers. Snake 28, 33-36.

Buckle, A., Fenn, M., 1992. Rodent control in the conservation of endangered species'. In: Vertebrate Pest Conference, vol. 15, pp. 36-41.

Clark, L., Savarie, P.J., 2012. Efficacy of aerial broadcast baiting in reducing brown treesnake numbers. Human Wildlife Interact. 6, 212-221.

Clark, L., Shivik, J.A., 1998. Brown treesnake repellents derived from natural products. In: Campbell III, E.W., Rodda, G.H. (Eds.), Brown Treesnake Research Symposium. 27-29 July, Honolulu, p. 13.

Clark, L., Shivik, J.A., 2002. Aerosolized essential oils and individual natural product compounds as brown treesnake repellents'. Pest Manag. Sci. 58, 775-783.

Clark, C.S., Vice, D.S., 2001. Protecting the endangered Vanikoro swiftlet from brown treesnakes. In: Brown Treesnake 2001 Research and Management. 6-10 August. Andersen Air Force Base, Guam, pp. 9-10.

Clark, L., Savarie, P.J., Shivik, J.A., Breck, S.W., Dorr, B.S., 2012. Efficacy, effort, and cost comparisons of trapping and acetaminophen-baiting for control of brown treesnakes on Guam'. Human Wildlife Interact. 6, 222-236.

Dorr, B.S., Clark, C., Vice, D., Pitt, W., Engeman, R., Savarie, P., 2014. Managing the Brown tree snake headache: history and preliminary insights of the aeria acetaminophen bait drop on Guam. In: Abstracts, 21st Annual Meeting of the Wildlife Society Conference, Pittsburgh. The Wildlife Society, Bethesda no PN.

Dorr, B.S., Clark, C., Vice, D., Engeman, R., Savarie, P., 2015. Managing the Brown treesnake headache: assessment of the aerial acetaminophen bait drop on Guam. In: Abstracts, 22nd Annual Meeting of the Wildlife Society Conference, Winnipeg. The Wildlife Society, Bethesda no PN.

Engbring, J., Pratt, H.D., 1985. Endangered birds in Micronesia: their history, status, and future prospects. In: Temple, S.A. (Ed.), Bird Conservation, vol. 2. University of Wisconsin Press, Madison, pp. 71-105.

Engeman, R.M., Linnell, M.A., 1998. Trapping strategies for deterring the spread of brown tree snakes (Boiga irregularis) from Guam. Pac. Conserv. Biol. 4, 348-353.

Engeman, R.M. Linnell, M.A. 2004. Effects of trap spacing on the capture of brown tree snakes on Guam. Int. Biodeterior. Biodegrad. 54, 265-267.

Engeman, R.M., Vice, D.S., 2001a. A direct comparison of trapping and spotlight searches for capturing brown tree snakes on Guam. Pac. Conserv. Biol. 7, 4-8.

Engeman, R.M., Vice, D.S., 2001b. Objectives and integrated approaches for the control of brown treesnakes. Integr. Pest Manag. Rev. 6, 59-76.

Engeman, R.M., Linnell, M.A., Pochop, P.A., Gamboa, J., 1998a. Substantial reductions of brown tree snake (Boiga irregularis) populations in blocks of land on Guam through operational trapping. Int. Biodegrad. Biodeterior. 42, 167-171.

Engeman, R.M., Rodriguez, D.V., Linnell, M.A., Pitzler, M.E., 1998b. A review of the case histories of brown tree snakes (Boiga irregularis) located by detector dogs on Guam. Int. Biodegrad. Biodeterior. 42, 161-165.

Engeman, R.M., Vice, D.S., Rodriguez, D.V., Gruver, K.S., Santos, W.S., Pitzler, M.E. 1998d. Effectiveness of detector dogs for locating brown tree snakes in cargo. Pac. Conserv. Biol. 4, 348-353.

Engeman, R.M., Linnell, M.A., Aguon, P., Manibusan, A., Sayama, S., Techaira, A., 1999 Implications of brown tree snake captures from fences. Wildl. Res. 26, 111-116.

Engeman, R.M. Vice, D.S., Nelson, G., Muna, E., 2000. Brown tree snakes effectively removed from a large plot of land on Guam by perimeter trapping. Int. Biodegrad. Biodeterior. 45, 139-142.

Engeman, R.M., Vice, D.S., York, D., Gruver, K.S., 2002. Sustained evaluation of the effectiveness of detector dogs for locating brown tree snakes in cargo outbound from Guam. Int. Biodeterior. Biodegrad. 49, 101-106.

Engeman, R.M., Jacobson, E., Avery, M.L., Meshaka Jr., W.E., 2011. The aggressive invasion of exotic reptiles in Florida with a focus on prominent species: a review. Curr. Zool. 57, 599-612.

Engeman, R.M., Avery, M.L., Shiels, A., Berentsen, A., VerCauteren, K., Sugihara, R. Duffiney, A., Clark, C.S., Eisemann, J., 2018. Diverse examples from managing invasive vertebrate species on inhabited islands of the United States. Australas. J. Environ. Manag. 25, 43-61.

Fagerstone, K.A., Eisemann, J.E., 2001. EPA registration requirements for use of acetaminophen to manage brown treesnake populations. In: Brown Treesnake 2001 Research and Management. 6-10 August. Andersen Air Force Base, Guam, pp. 10-11.

Fritts, T.H., 2002. Economic costs of electrical system instability and power outages caused by snakes on the island of Guam. Int Biodeterior. Biodegrad 49,93-100.

Fritts, T.H., McCoid, M.J., 1991. 'Predation by the brown tree snake (Boiga irregularis) on poultry and other domesticated animals on Guam. Snake 23, 75-80.

Fritts, T.H., Scott, N.J., Savidge, J.A., 1987. Activity of the arboreal brown tree snake (Boiga irregularis) on Guam as determined by electrical outages. Snake 19 $51-58$.

Fritts, T.H., McCoid, M.J., Haddock, R.L., 1990. Risks to infants on Guam from bites of the brown tree snake (Boiga irregularis). Am. J. Trop. Med. Hyg. 42, 607-611.

Fritts, T.H., McCoid, M.J., Haddock, R.L., 1994. Symptoms and circumstances associated with bites by the brown tree snake (Colubridae: Boiga irregularis) on Guam. J. Herpetol. 28, 27-33.

Fritts, T.H., McCoid, M.J., Gomez, D.M., 1999. Dispersal of snakes to extralimital islands: incidents of the brown treesnake (Boiga irregularis) dispersing to islands in ships and aircraft. In: Rodda, G., Sawai, Y., Chiszar, D., Tanaka, H. (Eds.), Problem Snake Management: Habu and Brown Treesnake. Cornell Univ. Press, Ithaca, NY, pp. 209-223.

Grue, C.E., 1985. Pesticides and the decline of Guam's native birds. Nature 316, 301
Hall, T.C., 1996. Operational control of the brown tree snake on Guam. In: Vertebrate Pest Conference, vol. 17, pp. 234-240.

Imler, R.H., 1945. Bullsnakes and their control on a Nebraska wildlife refuge. J. Wildl. Manag. 9, 265-273.

Kimball, B.A., Scott, A., Stelting, S.A., McAuliffe, T.W., Stahl, R.S., Garcia, R.A., Pitt, W.C., 2016. Development of artificial bait for brown treesnake suppression. Biol. Inv. 18, 359-369.

Kraus, F., 2009. Alien Reptiles and Amphibians: a Scientific Compendium and Analysis. Springer Science \& Business Media, The Netherlands.

Kraus, F., Stahl, R., Pitt, W., 2015. Thermal fumigation provides a simple and effective solution for sanitizing cargo from invasive snakes. J. Pest Sci. 88, 331-341.

Linnell, M.A., Engeman, R.M., Pitzler, M.E., Watten, M.O., Whitehead, G.F., Miller, R.C., 1998. An evaluation of two designs of stamped metal trap flaps for use in the operational control of brown tree snakes (Boiga irregularis). Snake 28, 14-18.

Lynch, J.A., Sugihara, R.T., Vice, D.S., Campbell III, E., Salas, A., Mathews, R. Cascasan, G., Kendall, M., Quitugua, J., 2001. Large-scale brown treesnake control on Andersen Air Force Base's munitions storage area, Guam: year one summary. In: Brown Treesnake 2001 Research and Management. 6-10 August. Andersen Air Force Base, Guam, p. 11.

Mathies, T., Levine, B., Engeman, R.M., Savidge, J.A., 2013. Pheromonal control of the invasive brown treesnake: female sexual attractiveness pheromone varies with ovarian state. Int. J. Pest Manag. 59, 141-149.

McCoid, M.J., Fritts, T.H., Campbell III, E.W., 1994. A brown tree snake (Colubridae: Boiga irregularis) sighting in Texas. Tex. J. Sci. 46, 365-368.

Office of Insular Affairs/U.S. Department of Interior, 2015. Interior Provides \$3.7 Million for Brown Tree Snake Control, Interdiction, and Prevention in Western Pacific and Hawaii. News Release. U.S. Department of Interior, Washington DC.

Ohashi, T.J., Oldenburg, J.G., 1992. Endangered species in the pacific islands: the role of animal damage control. In: Vertebrate Pest Conference, vol. 15, pp. 32-35.

Perry, G., Vice, D.S., 1998. Evaluating the risk of brown treesnake dispersal in surface and air shipping: lessons from thermal research. In: Campbell III, E.W., Rodda, G.H. (Eds.), Brown Treesnake Research Symposium. 27-29 July, Honolulu, p. 30.

Perry, G., Campbell III, E.,W., Rodda, G.H., Fritts, T.H., 1998. Managing island biotas: brown treesnake control using barrier technology. In: Vertebrate Pest Conference, vol. 18, pp. 138-143.

Perry, G., Rodda, G.H., Fritts, T.H., Qualls, F.J., 2001. Snake control using barrier technology: a summary of work conducted 1995-2001. In: Brown Treesnake 2001 Research and Management. 6-10 August. Andersen Air Force Base, Guam, p. 15.

Rawlings, L.R., Whittier, J., Mason, R.T., Donnellan, S.C., 1998. Phylogenetic analysis of the brown treesnake, Boiga irregularis, particularly relating to a population on Guam. In: Campbell III, E.W., Rodda, G.H. (Eds.), Brown Treesnake Research Symposium. 27-29 July, Honolulu, p. 31.

Richmond, J.Q., Wood, D.A., Stanford, J.W., Fisher, R.N., 2015. Testing for multiple invasion routes and source populations for the invasive brown treesnake (Boiga irregularis) on Guam: implications for pest management. Biol. Inv. 17, 337-349.

Rodda, G.H., 1991. Fence climbing by the arboreal brown tree snake, Boiga irregularis. Snake 23, 101-103.

Rodda, G.H., Fritts, T.H., 1992a. The impact of the introduction of the colubrid snake Boiga irregularis on Guam's lizards. J. Herpetol. 26, 166-174.

Rodda, G.H., Fritts, T.H., 1992b. Sampling techniques for an arboreal snake, Boiga irregularis. Micronesica 25, 23-40.

Rodda, G.H., Fritts, T.H., Perry, G., Campbell III, E.W., 1998. Managing island biotas: can indigenous species be protected from introduced predators such as the brown treesnake?. In: Trans. 63rd North American Wildlife and Natural Resources Conference, pp. 95-108.

Rodda, G.H., Fritts, T.H., McCoid, M.J., Campbell III, E.W., 1999. An overview of the biology of the brown treesnake (Boiga irregularis), a costly introduced pest on Pacific islands. In: Rodda, G., Sawai, Y., Chiszar, D., Tanaka, H. (Eds.), Problem Snake Management: Habu and Brown Treesnake. Cornell Univ. Press, Ithaca, NY, pp. $44-80$.

Saipan Tribune Press Release, 2017. Snake Program Obtains Two New ‘sniffer' Dogs. Press Release| Posted on Nov 20. 2017.

Savarie, P.J., 2012. Development of Non-prey Baits for Delivery of Acetaminophen to Brown Treesnakes (Boiga Irregularis) on Guam. SERDP Project Number: RC1732. USDA/National Wildlife Research Center, Fort Collins, CO.

Savarie, P... Clark, L., 2006. Evaluation of bait matrices and chemical lure attractants for Brown tree snakes. In: Vertebrate Pest Conference, vol. 22, pp. 483-488.

Savarie, P.J., Brooks, J.E., York, D.L., Hurley, J.C., Volz, S., 2000. Testing the dermal and oral toxicity of selected chemicals to brown tree snakes (Boiga irregularis). In: Vertebrate Pest Conference, vol. 19, pp. 139-145.

Savarie, P.J., Linder, T.J., York, D.L., 2001a. Acetaminophen feeding tests in land hermit crabs (Coenobita brevimanus) and coconut crabs (Birgus latro). In: Brown Treesnake 2001 Research and Management. 6-10 August. Andersen Air Force Base, Guam, p. 20.

Savarie, P.J., Linder, T.J., York, D.L., 2001b. Video camera monitoring of dead mice (Mus musculus) and brown treesnakes (Boiga irregularis). In: Brown Treesnake 2001 Research and Management. 6-10 August. Andersen Air Force Base, Guam, pp. 20-21.

Savarie, P.J., Shivik, J.A., White, G.C., Hurley, J.C., Clark, L., 2001c. Use of acetaminophen for large scale control of brown treesnakes. J. Wildl. Manag. 65, 356-365.

Savarie, P.J., Wood, S., Rodda, G., Bruggers, R.L., Engeman, R.M., 2005. Effectiveness of methyl bromide as a cargo fumigant for brown treesnakes. Int. Biodeterior. 
Biodegrad. 56, 40-44.

Savidge, J.A., 1987. Extinction of an island forest avifauna by an introduced snake. Ecology 68, 660-668.

Savidge, J.A., 1988. Food habits of Boiga irregularis, an introduced predator on Guam. J. Herpetol. 22, 275-282.

Savidge, J.A., Sileo, L., Siegfried, L.M., 1992. Was disease involved in the decimation of Guam's avifauna? J. Wildl. Dis. 28, 206-214.

Savidge, J.A., Stanford, J.W., Reed, R.N., Haddock, G.R., Adams, A.A.Y., 2011. Canine detection of free-ranging brown treesnakes on Guam. N. Z. J. Ecol. 35, 174-181.

Shivik, J.A., Clark, L., 1999. Ontogenetic shifts in carrion attractiveness to brown tree snakes (Boiga irregularis). J. Herpetol. 33, 334-336.

Shwiff, S.A., Gebhardt, K., Kirkpatrick, K.N., Shwiff, S.S., 2010. Potential economic damage from introduction of Brown tree snakes, Boiga irregularis (reptilia: colubridae), to the islands of Hawai'i'. Pac. Sci. 64, 1-10.

Stanford, J.W., Rodda, G.H., 2007. In: Witmer, G.W., Pitt, W.C., Fagerstone, K.A. (Eds.), Managing Vertebrate Invasive Species: Proceedings of an International Symposium. National Wildlife Research Center, Fort Collins, Colorado, pp. 127-132.

U.S. Department of Agriculture/Animal and Plant Health Inspection Service, U.S. Department of Agriculture/Forest Service, Department of Interior/Bureau of Land Management, 1997. Animal Damage Control Program Final Environmental Impact Statement (Revised). USDA/Animal and Plant Health Inspection Service, Washington, D.C.

U.S. Fish and Wildlife Service, 2009. Ko'ko' or Guam Rail (Gallirallus Owstoni) 5-Year Review Summary and Evaluation. U.S. Fish and Wildlife Service Pacific Islands Fish and Wildlife Office, Honolulu.

USDoD (U.S. Department of Defense), 2008. Control of the Brown Tree Snake (BTS). Report to the Congress. U.S. Department of Defense, Washington DC.
Vice, D.S., 2011. Brown Treesnake Interdiction and Prevention of Spread. Project Number 05-238. Department of Defense Legacy Resource Management Program. Department of Defense, Washington, DC.

Vice, D.S., Engeman, R.M., 2000. Brown tree snake discoveries during detector dog inspections following Supertyphoon Paka. Micronesica 33, 105-110.

Vice, D.S., Pitzler, M.E., 2002. Brown treesnake control: economy of scales. In: Clark, L. (Ed.), Human Conflicts with Wildlife: Economic Considerations, Proceedings of the Third NWRC Special Symposium. National Wildlife Research Center, Fort Collins, Colorado, pp. 127-132.

Vice, D.L., Beck, R., Aguon, C.F., Medina, S., 2001. Recovery of native bird species on Guam. In: Brown Treesnake 2001 Research and Management. 6-10 August. Andersen Air Force Base, Guam, pp. 24-25.

Vice, D.S., Linnell, M.A., Pitzler, M.E., 2002. Summary of Guam's Outbound Cargo Process: Preventing the Spread of the Brown Tree Snake. Working Draft Report. USDA/APHIS/Wildlife Services, Guam District.

Vice, D.S., Engeman, R.M., Vice, D.L., 2005. A comparison of three trap designs for capturing brown treesnakes on Guam. Wildl. Res. 32, 355-359.

Vice, D.S., Engeman, R.M., Hall, M.A., Clark, C.S., 2009. Working dogs: the last line of defense for preventing the dispersal of brown tree snakes from Guam. In: Helton, W.S. (Ed.), Canine Ergonomics: the Science of Working Dogs. CRC Press, New York, pp. 195-204.

Wiles, G.J., 1987a. The status of fruit bats on Guam. Pac. Sci. 41, 148-157.

Wiles, G.J., 1987b. Current research and future management of Marianas fruit bats (Chiroptera: pteropodidae) on Guam. Aust. Mammal. 10, 93-95.

Wiles, G.J., Aguon, C.F., Davis, G.W., Grout, D.J., 1995. The status and distribution of endangered animals and plants in northern Guam. Micronesica 28, 31-49. 